
\title{
3 Research Square \\ Female Breast Cancer Trends in Disaggregated Asian American Populations: Analysis of 2003-2017 U.S. Mortality Data
}

Vaishnavi Bhamidi ( $\nabla$ vbhamidi@stanford.edu )

Stanford Center for Asian Health Research and Education https://orcid.org/0000-0002-6317-6463

Nathaniel Islas

Stanford Center for Asian Health Research and Education

Caroline Feng

Stanford Center for Asian Health Research and Education

Naveli Garg

Stanford Center for Asian Health Research and Education

Kevin Xi

Stanford Center for Asian Health Research and Education

Robert Huang

Stanford University School of Medicine

Timothy Au

Stanford Center for Asian Health Research and Education

Nora Sharp

Stanford Center for Asian Health Research and Education

Allison W. Kurian

Stanford University School of Medicine

Latha Palaniappan

Stanford University School of Medicine

Sukyung Chung

Stanford University School of Medicine

Caroline A. Thompson

San Diego State University Graduate School of Public Health

Malathi Srinivasan

Stanford University School of Medicine

\section{Research Article}

Keywords: Breast cancer, Non-Hispanic White (NHW), Age-adjusted mortality rates (AAMR), proportional mortality rates (PMR). 
Posted Date: May 27th, 2021

DOl: https://doi.org/10.21203/rs.3.rs-416046/v1

License: (c) (i) This work is licensed under a Creative Commons Attribution 4.0 International License. Read Full License 


\section{Abstract}

\section{Purpose}

Breast cancer is the second leading cause of female cancer mortality in the United States and breast cancer mortality in Asian Americans (AA) is rising by $1.5 \%$ per year. However, aggregated AA breast cancer death rates may mask important mortality differences in major AA groups.

Population \& Setting

11,388 AA and 473,927 non-Hispanic White (NHW) females based on the United States Centers for Disease Control and Prevention National Vital Statistics System database 2003-2017.

Methods

Age-adjusted mortality rates (AAMR) were used to estimate trends in breast cancer mortality in Asian Indians, Chinese, Filipinas, Japanese, Koreans, Vietnamese, and non-Hispanic Whites from 2003-2017, with attention to annual percentage change (APC) and proportional mortality rates (PMR).

Results

From 2003-2017, breast cancer deaths comprised $14.4 \%$ in NHWs, $13.7 \%$ in aggregate AAs, $19.8 \%$ in Asian Indians, and $18.6 \%$ of all cancer deaths in Filipinas. While NHW breast cancer mortality rate significantly decreased (APC $-2.1 ; \mathrm{Cl}-2.6,-1.6 ; \mathrm{p}<0.001$ ) from 2003 to 2017, aggregate AA mortality rates were unchanged (APC 3.07; $\mathrm{Cl}-0.37,7.8 ; \mathrm{p}=0.071$ ). However, when disaggregated, breast cancer mortality in Filipina (APC 1.9; Cl 0.8, 3.0; $<<0.002$ ), Chinese (APC 2.1; Cl 1.3, 3.0; $<<0.001$ ), and Korean (APC 2.6; $\mathrm{Cl} 1.0,4.1 ; \mathrm{p}=0.004$ ) women significantly increased. Breast cancer mortality rates in Japanese women decreased (APC -1.9; $\mathrm{Cl}-5.9,2.1 ; \mathrm{p}=0.3$ ).

\section{Conclusion}

While the proportion of women dying from breast cancer were similar in NHWs and aggregate Asians, when disaggregated, Filipina, Korean, and Chinese women had increased mortality rates over the past 15 years. During this time, breast cancer mortality in NHW and Japanese women decreased. Understanding disaggregated breast cancer mortality rates in Asians may improve culturally-tailored outreach, prevention, and treatment strategies to reduce cancer deaths from this critical disease.

\section{Introduction}

In the United States, 1 in 8 women (12\%) will be diagnosed with invasive breast cancer in their lifetime and 1 in 39 women (3\%) will die due to breast cancer ${ }^{1}$. Efforts such as emerging treatments and more aggressive screening practices have significantly reduced breast cancer mortality by $40 \%$ from 1989 to 
$2017^{1}$. Despite this progress, breast cancer is still predicted to be the leading form of new cancer diagnosed in 2020 and will account for $30 \%$ of all predicted cancer cases in all American females ${ }^{2}$.

When aggregated, women with Asian/Pacific Islander ancestry appear to have the lowest breast cancer incidence $(93.7$ per 100,000$)$ and death $(14$ per 100,000$)$ rates of all American racial groups ${ }^{1}$, but the aggregate Asian American (AA) breast cancer incidence has been increasing by $1.5 \%$ yearly ${ }^{3,4}$. With over 17.3 million AAs in the U.S. in 2010, this rate of increase in breast cancer indicates a significant healthcare burden ${ }^{5,6}$.

The distinct ethnic subgroups comprising the AA population are extremely diverse in country of origin, length of US residence, acculturation, socioeconomic status, language, culture, religion, and more ${ }^{7-10}$. By aggregating all AAs into a single group, health care providers and policy makers may miss critical heterogeneity around breast cancer healthcare and mortality ${ }^{11}$. For example, Thompson et al. examined disaggregated death certificate data of AAs (Asian Indian, Korean, Japanese, Chinese, Vietnamese, and Filipino) from 2003 to 2011 and found that female Filipino Americans had the highest comparative rates of breast cancer amongst the six AA ethnic groups, even if the aggregated AA death rates trended downward ${ }^{12}$. However, this study did not find any significant breast cancer mortality trends for any of the AA groups.

In this study, we present updated trends in female breast cancer mortality rates from 2012 to 2017 among six disaggregated AA ethnicities in comparison with Non-Hispanic White (NHW) females using the Centers for Disease Control and Prevention (CDC) National Vital Statistics System (NVSS) mortality dataset. We also compare current breast cancer mortality trends to previous trends from 2003 to 2011 .

\section{Methods}

\section{Data}

U.S. mortality records between 2003 to 2017 for all fifty states were obtained under an IRB data-use agreement from the CDC NVSS mortality dataset (Protocol \# 53429). Death certificates were completed by clinicians and/or medical coroners at time of death and include information about age, sex, race/ethnicity, and cause of death. Underlying causes of death were classified by the International Classification of Diseases (ICD), 10th revision. ICD-10 code C50 (malignant neoplasm of the breast) identified breast cancer as the primary underlying cause of death. Other variables of interest included sex and age.

\section{Participants}

Female NHWs and AAs within six ethnic groups were included: Asian Indians, Chinese, Filipinos, Japanese, Koreans, Vietnamese. Hispanics, African American or Black, Pacific Islanders, and any AAs not in the six selected subgroups were excluded. Males were also excluded from the study. Incomplete death certificates (decedents with missing data for age and primary cause of death variables) and individuals 
with mixed racial identity or unknown age were excluded. Data analysis was conducted for 473,927 NHW females and 11,388 AA females (1425 Asian Indians, 2898 Chinese, 3865 Filipina, 1549 Japanese, 949 Korean, 702 Vietnamese) (Fig. 1).

\section{Statistical Analysis}

Three different numerical measures were calculated: age-adjusted mortality rates (AAMR), standardized mortality ratios (SMR), and proportionate mortality. AAMR was calculated as the deaths per 100,000 people. Annual percentage change (APC) was calculated as the average percentage change in the fifteenyear period. SMR was calculated as a ratio of the AAMRs with NHW as the reference. Proportionate mortality was calculated as the proportion of breast cancer deaths compared to all cancer deaths. Population counts were extrapolated based on the 2003 and 2010 US Census. To account for the rolling adoption of the 2003 death certificate by state, population adjustment was conducted by enrolling descendants from each state as disaggregated information became available ${ }^{13}$. Death and population data from each state were included in the numerator and denominator, respectively, when that state adopted the 2003 death certificate. For AAMRs from 2003-2017, age adjustment was calculated using the 2010 US standard age distribution of the population. The same standard age distribution was applied to each group's age-specific mortality rates in order to compare groups. Nativity population data for each of the six AA subgroups was gathered from the American Community Survey (ACS $)^{14}$. We did not suppress data with $<10$ deaths per cell. A linear model, and not a joinpoint analysis, to analyze the overall trend.

\section{Results}

\section{Results for Aggregate AAs}

We identified 624,221 female AA decedents and 30,269,449 female NHW decedents over the fifteen-year study period, of whom 612,833 female AAs and 30,222,057 female NHWs were excluded and 11,388 female AAs and 473,927 female NHWs died of breast cancer (Supplementary Fig. 1). Overall, 13.7\% of aggregate female $\mathrm{AA}$ and $14.4 \%$ female NHW cancer deaths were from breast cancer. AAMRs within disaggregated female AAs ranged from 3.5 per 100,000 (Vietnamese) to 21.6 per 100,000 (Filipina) (Fig. 2 and Supplementary Fig. 2).

\section{Results for Disaggregated AAs}

Breast cancer death rates over time: Temporal AAMR rates demonstrated a significant decrease in NHW breast cancer mortality (APC - 2.11; Cl -2.63 -1.60; $\mathrm{p}<0.001)$ while breast cancer mortality in aggregate AAs was AAs was increasing, but not significantly (APC 3.07; Cl -0.37 6.50; p < 0.05) (Fig. 2 and Supplementary Fig. 2). However, when AAs were disaggregated, Filipinas consistently had the highest AAMR rates, while Japanese women had the lowest rates (Fig. 2 and Supplementary Fig. 2). In addition, Filipinas had a significantly increasing trend (APC 1.75; Cl 0.98 2.53; p < 0.001), as did Chinese (APC 2.00; Cl 1.06 2.92; $p<0.001$ ) and Korean (APC 1.98; Cl 0.58 3.36, $p<0.01$ ) women. Japanese women had an 
insignificant decreasing breast cancer mortality trend (APC - 1.88; $\mathrm{Cl}-5.882 .1, \mathrm{p}=0.33$ ). Asian Indians (APC - 0.06; Cl -2.25 2.37; $p=0.96$ ) and Vietnamese women (APC 1.72; $\mathrm{Cl}-0.013 .45 ; \mathrm{p}=0.05$ ) had stable breast cancer mortality rates with no significant trends.

Proportion of breast cancer deaths: Although proportionate mortality of breast cancer deaths compared to all cancer deaths for aggregate AAs (13.7\%) and NHWs (14.4\%) appear comparable, the disaggregated AA ethnicities show great variability (Fig. 4). Asian Indians (19.8\%) and Filipinas (18.6\%) had the highest proportion of breast cancer deaths, as well as NHWs (14.4\%). On the other end, Korean (10.0\%), Japanese $(10.7 \%)$, and Vietnamese women (10.5\%) had the lowest proportion of breast cancer mortality.

\section{Nativity Analysis}

An analysis of breast cancer mortality trends from 2003-2017 for each of the six Asian groups showed no significant differences by place of birth, except for Japanese women (Fig. 5). US-born Japanese women had decreasing rates of breast cancer deaths (APC - 1.0; $\mathrm{Cl}-1.7-2.4 ; \mathrm{p} \mathrm{0.0001)}$, while breast cancer deaths increased in foreign-born Japanese (APC 11.4; Cl $0.86 .12 ; \mathrm{p} \mathrm{0.02)} \mathrm{(Fig.} 6$ and Supplementary Fig. 3).

\section{Discussion}

Over the past 15 years, we found that non-Hispanic white women have exhibited steadily decreasing breast cancer mortality trends (about 2.1\% annually), while the aggregate Asian Americans breast cancer deaths have remained stable. However, when AAs groups are disaggregated, they demonstrate considerable heterogeneity. Specifically, we found that Filipina, Korean and Chinese women have about a $2 \%$ annual increase in breast cancer deaths. Moreover, Filipina women had the highest age-adjusted breast cancer rates which were about two times higher than aggregate AAs. By contrast, Vietnamese, Asian Indians, and aggregated AAs exhibited a stable breast cancer mortality trend. While aggregated proportions of cancer deaths were the same for NHW and AA (about 14\%), when disaggregated, AA groups demonstrated broad variability in mortality. The large variability in breast cancer mortality rates by AA groups corresponds to results from earlier studies. Thompson et al., found that Filipinas had the highest rate of breast cancer, contributing to $19.5 \%$ of all Filipina cancer deaths ${ }^{12}$. They also found $19.8 \%$ of all Asian Indian cancer deaths were from breast cancer, now the leading cause of all Asian Indian cancer deaths. These findings might be influenced by cancer type, hormone therapy, access to care, screening and lifestyle behaviors amongst women within each AA group.

High but stable breast cancer mortality in Asian Indian women and low but stable mortality in Vietnamese women may be influenced by cancer type. Asian Indians are more likely than NHWs to have triple-negative breast cancer ${ }^{15-17}$, which is relatively uncommon and, until recently, without curative targeted therapies ${ }^{18-19}$. Conversely, Vietnamese women are more likely to have HER2-positive breast cancer $^{20}$, which can have a poor prognosis if not treated optimally with targeted therapies ${ }^{21}$. The stable breast cancer mortality among Asian Indian and Vietnamese women may also be influenced by access to 
care $^{22}$. Increasing AA breast cancer mortality may be driven by post-menopausal hormone replacement therapy $(\mathrm{HRT})^{23}$. Breast cancer risk increased $26 \%$ per 5 years of current use of estrogen and progestin therapy $(p=0.017)$ in a study of 1,277 Chinese, Japanese, and Filipinas ${ }^{24}$. Asian and Pacific Islander postmenopausal women may be at higher risk for developing breast cancer (OR 1.58; $95 \% \mathrm{Cl}$ of 1.18 2.11) than NHW women (OR $1.21 ; 95 \% \mathrm{Cl} 1.14-1.28)$ after using $\mathrm{HRT}^{25}$.

Increasing breast cancer mortality in Filipina, Chinese, and Korean women may be due to lack of preventative public health measures, including screening ${ }^{26-28}$ and treatment ${ }^{29}$. AA cancer screening rates are lower than those of $\mathrm{NHWs}$ for all cancer types ${ }^{30}$ and AA women (65\%) tend to have lower breast cancer screening rates than $\mathrm{NHWs}(68 \%)^{31}$. In a study comparing mammography rates among AA subgroups, South Asian and Korean women had the lowest mammography rates while Japanese women had the highest rates, second only to NHW women ${ }^{7}$. By contrast, Korean American women had the lowest rates of breast cancer screening ${ }^{32}$. Acculturation, healthcare access, and low levels of health literacy have been posited as potential reasons for reduced breast cancer screening in $A A s^{30,33-35}$. Breast cancer screening rates also vary between the AA subgroups ${ }^{26}$.

Lower levels of screening, perhaps coupled with an increase in risk factors associated with a Western lifestyle (e.g., obesity, alcohol, tobacco, unopposed continuous estrogen from reduced and/or delayed parity) may contribute to increasing breast cancer mortality trends within Korean women. In addition, screening behaviors vary by Asian American group. A meta-analysis found that only $34-65 \%$ of Korean women aged $50-74$ reported obtaining a mammogram within the last two years, compared to $73 \%$ of white women and $72 \%$ of other Asian women ${ }^{36}$. Mammography screening among Korean American women in the past two decades has also significantly increased, but these rates are still much lower than $\mathrm{NHWs}$, especially since Korean American women tended to be uninsured and sought out professionals from South Korea where preventative health measures are unusual ${ }^{26}$. Consistent with their lower utilization of mammography screening, Korean women were twice as likely to be diagnosed with a tumor size $>1 \mathrm{~cm}$ as compared to White women (OR 2.38; $\mathrm{Cl} 1.493 .80)^{37}$.

Amongst Asians, Japanese women had the lowest rates of breast cancer mortality. Not only have Japanese American women been shown to have increased mammography rates compared to other Asians ${ }^{38}$, Japanese American women with breast cancer also had a lower risk of having advanced-stage disease than NHW women or those in other Asian subgroups ${ }^{39}$. Increased adoption of breast screening among Japanese may be driven by a larger proportion of acculturated, highly educated, and wealthier Japanese American women as compared by other AA ethnicities ${ }^{8,40}$.

Our study has several limitations. While we captured all deaths in the United States, ethnic/racial groups may have been misclassified unintentionally by the healthcare provider or funeral director completing the death certificate, especially if next-of-kin or family members were not present ${ }^{41}$. However, ethnicity misclassification has been diminishing over time, and are estimated at $3 \%$ for Asian Pacific Islanders ${ }^{41}$. States' adoption of the 2003 death certificate Asian subgroup classification occurred over time, although 
the states with the largest Asian populations were among the earlier adopters ${ }^{13}$. Finally, as death certificate data are not linked to other medical information, no information is available about other socioeconomic data that might inform further mortality-related analysis.

\section{Conclusion}

Breast cancer mortality may be improved with healthy lifestyles, early diagnosis via mammographic screening, tailored treatment, and ongoing follow-up. The high and often increasing rates of breast cancer mortality among specific Asian American groups point to the need to disaggregate AA subgroups during research studies, to ensure that potential disparities in access to effective screening, treatment and follow-up care do not go unnoticed and unresolved.

\section{Declarations}

\section{Funding}

This study was funded and supported by the Stanford Center for Asian Health Research and Education, Palo Alto, CA.

\section{Conflicts of Interest}

The authors have no conflicts of interest to declare that are relevant to the content of this article.

Availability of Data and Material

The datasets generated during and/or analysed during the current study are available from the corresponding author on reasonable request

Code Availability.

R Studio, Version 3.6.1

\section{References}

1. American Cancer Society. Breast Cancer Facts \& Figures 2019-2020. Atlanta: American Cancer Society, Inc. 2019.

2. American Cancer Society. Cancer Facts \& Figures 2020. Atlanta: American Cancer Society; 2020.

3. DeSantis CE, Ma J, Gaudet MM, et al. Breast cancer statistics, 2019. CA A Cancer J Clin. 2019;69(6):438-451. doi:10.3322/caac.21583

4. Gomez SL, Noone A-M, Lichtensztajn DY, et al. Cancer Incidence Trends Among Asian American Populations in the United States, 1990-2008. J Natl Cancer Inst. 2013;105(15):1096-1110. doi:10.1093/jnci/djt157 
5. Hoeffel EM, Rastogi S, Kim MO, Shahid H. The Asian Population: 2010.

6. Wu AH, Stram DO, Hamilton AS. Resources and Methods for Studying Cancer Among Asian Americans. In: Cancer Epidemiology Among Asian Americans. Springer International Publishing; 2016. doi:10.1007/978-3-319-41118-7

7. McCracken $M$, Olsen M, Chen MS, et al. Cancer Incidence, Mortality, and Associated Risk Factors Among Asian Americans of Chinese, Filipino, Vietnamese, Korean, and Japanese Ethnicities. CA: A Cancer Journal for Clinicians. 2007;57(4):190-205. doi:10.3322/canjclin.57.4.190

8. Pew Research Center. The Rise of Asian Americans. Washington, DC: Pew Research Center; 2012.

9. Asian American Center for Advancing Justice. A Community of Contrasts-Asian Americans in the United States: 2011. Washington, DC: Asian American Center for Advancing Justice; 2011:1-68.

10. Torre LA, Goding Sauer AM, Chen MS, Kagawa-Singer M, Jemal A, Siegel RL. Cancer Statistics for Asian Americans, Native Hawaiians, and Pacific Islanders, 2015: Convergence of incidence between males and females. CA Cancer J Clin. 2016;66(3):182-202. doi:10.3322/caac.21335

11. Srinivasan S, Guillermo T. Toward improved health: disaggregating Asian American and Native Hawaiian/Pacific Islander data. Am J Public Health. 2000;90(11):1731-1734. doi:10.2105/AJPH.90.11.1731

12. Thompson CA, Gomez SL, Hastings KG, et al. The Burden of Cancer in Asian Americans: A Report of National Mortality Trends by Asian Ethnicity. Cancer Epidemiology Biomarkers \& Prevention. 2016;25(10):1371-1382. doi:10.1158/1055-9965.EPI-16-0167

13. Thompson CA, Boothroyd DB, Hastings KG, Cullen MR, Palaniappan LP, Rehkopf DH. A MultipleImputation "Forward Bridging" Approach to Address Changes in the Classification of Asian Race/Ethnicity on the US Death Certificate. American Journal of Epidemiology. 2018;187(2):347-357. doi:10.1093/aje/kwx215

14. Steven Ruggles, Sarah Flood, Ronald Goeken, Josiah Grover, Erin Meyer, Jose Pacas and Matthew Sobek. IPUMS USA: Version 10.0. Minneapolis, MN: IPUMS, 2020. https://doi.org/10.18128/D010.V10.0

15. Kakarala M, Rozek L, Cote M, Liyanage S, Brenner DE. Breast cancer histology and receptor status characterization in Asian Indian and Pakistani women in the U.S. - a SEER analysis. BMC Cancer. 2010;10(1):191. doi:10.1186/1471-2407-10-191

16. Parise $C$, Caggiano V. Disparities in the risk of the ER/PR/HER2 breast cancer subtypes among Asian Americans in California. Cancer Epidemiology. 2014;38(5):556-562. doi:10.1016/j.canep.2014.08.001

17. Denkert C, Liedtke C, Tutt A, Von Minckwitz G. Molecular alterations in triple-negative breast cancerthe road to new treatment strategies. The Lancet. 2017;389(10087):2430-2442. doi:10.1016/S01406736(16)32454-0

18. McCann KE, Hurvitz SA, McAndrew N. Advances in Targeted Therapies for Triple-Negative Breast Cancer. Drugs. 2019;79(11):1217-1230. doi:10.1007/s40265-019-01155-4 
19. Telli ML, Chang ET, Kurian AW, et al. Asian ethnicity and breast cancer subtypes: a study from the California Cancer Registry. Breast Cancer Res Treat. 2011;127(2):471-478. doi:10.1007/s10549-0101173-8

20. Arteaga CL, Sliwkowski MX, Osborne CK, Perez EA, Puglisi F, Gianni L. Treatment of HER2-positive breast cancer: current status and future perspectives. Nature Reviews Clinical Oncology. 2012;9(1):16-32. doi:10.1038/nrclinonc.2011.177

21. Loibl S, Gianni L. HER2-positive breast cancer. The Lancet. 2017;389(10087):2415-2429. doi:10.1016/S0140-6736(16)32417-5

22. Gradishar WJ, Anderson BO, Abraham J, et al. Breast Cancer, Version 3.2020, NCCN Clinical Practice Guidelines in Oncology. J Natl Compr Canc Netw. 2020;18(4):452-478. doi:10.6004/jnccn.2020.0016

23. Coombs NJ, Cronin KA, Taylor RJ, Freedman AN, Boyages J. The impact of changes in hormone therapy on breast cancer incidence in the US population. Cancer Causes Control. 2010;21(1):83-90. doi:10.1007/s10552-009-9437-5

24. Wu AH, Yu MC, Tseng C-C, Pike MC. Body size, hormone therapy and risk of breast cancer in AsianAmerican women. International Journal of Cancer. 2007;120(4):844-852. doi:https://doi.org/10.1002/ijc.22387

25. Hou N, Hong S, Wang W, Olopade OI, Dignam JJ, Huo D. Hormone replacement therapy and breast cancer: heterogeneous risks by race, weight, and breast density. J Natl Cancer Inst. 2013;105(18):1365-1372. doi:10.1093/jnci/djt207

26. Oh KM, Taylor KL, Jacobsen KH. Breast Cancer Screening Among Korean Americans: A Systematic Review. J Community Health. 2017;42(2):324-332. doi:10.1007/s10900-016-0258-7

27. Sadler GR, Wang K, Wang M, Ko CM. Chinese women: behaviors and attitudes toward breast cancer education and screening. Women's Health Issues. 2000;10(1):20-26. doi:10.1016/S10493867(99)00046-8

28. Ko CM, Sadler GR, Ryujin L, Dong A. Filipina American women's breast cancer knowledge, attitudes, and screening behaviors. BMC Public Health. 2003;3(1):27. doi:10.1186/1471-2458-3-27

29. Gelber RP, McCarthy EP, Davis JW, Seto TB. Ethnic Disparities in Breast Cancer Management Among Asian Americans and Pacific Islanders. Ann Surg Oncol. 2006;13(7):977-984. doi:10.1245/ASO.2006.08.036

30. Shi L, Lebrun LA, Zhu J, Tsai J. Cancer screening among racial/ethnic and insurance groups in the United States: a comparison of disparities in 2000 and 2008. J Health Care Poor Underserved. 2011;22(3):945-961. doi:10.1353/hpu.2011.0079

31. Ryu SY, Crespi CM, Maxwell AE. What Factors Explain Disparities in Mammography Rates Among Asian-American Immigrant Women? A Population-Based Study in California. Women's Health Issues. 2013;23(6):e403-e410. doi:10.1016/j.whi.2013.08.005

32. Sentell T, Braun KL, Davis J, Davis T. Health literacy and meeting breast and cervical cancer screening guidelines among Asians and whites in California. Springerplus. 2015;4:432. doi:10.1186/s40064-015-1225-y 
33. Kandula NR, Wen M, Jacobs EA, Lauderdale DS. Low rates of colorectal, cervical, and breast cancer screening in Asian Americans compared with non-Hispanic whites. Cancer. 2006;107(1):184-192. doi:10.1002/cncr.21968

34. Lee S, Chen L, Jung MY, Baezconde-Garbanati L, Juon H-S. Acculturation and Cancer Screening Among Asian Americans: Role of Health Insurance and Having a Regular Physician. J Community Health. 2014;39(2):201-212. doi:10.1007/s10900-013-9763-0

35. Lee HY, Ju E, Vang PD, Lundquist M. Breast and Cervical Cancer Screening Disparity Among Asian American Women: Does Race/Ethnicity Matter? Journal of Women's Health. 2010;19(10):1877-1884. doi:10.1089/jwh.2009.1783

36. Hedeen AN, White E, Taylor V. Ethnicity and birthplace in relation to tumor size and stage in Asian American women with breast cancer. Am J Public Health. 1999;89(8):1248-1252. doi:10.2105/AJPH.89.8.1248

37. McPherson K, Steel CM, Dixon JM. Breast cancer-epidemiology, risk factors, and genetics. BMJ. 2000;321(7261):624-628.

38. Liu L, Zhang J, Wu AH, Pike MC, Deapen D. Invasive breast cancer incidence trends by detailed race/ethnicity and age. Int J Cancer. Published online 2012:10.

39. Hou N, Hong S, Wang W, Olopade OI, Dignam JJ, Huo D. Hormone replacement therapy and breast cancer: heterogeneous risks by race, weight, and breast density. J Natl Cancer Inst. 2013;105(18):1365-1372. doi:10.1093/jnci/djt207

40. Access Versus Acculturation: Identifying Modifiable Factors to Promote Cancer Screening Among Asian American Women. Published online 2021:10.

41. The Validity of Race and Hispanic-Origin Reporting on Death Certificates in the United States: An Update. Centers for Disease Control and Prevention; 2016:29.

\section{Figures}




\begin{tabular}{|c|c|c|c|c|c|c|c|c|}
\hline & $\begin{array}{c}\text { Non-Hispanic } \\
\text { White }\end{array}$ & $\begin{array}{c}\text { Aggregate } \\
\text { Asian }\end{array}$ & $\begin{array}{c}\text { Asian } \\
\text { Indian }\end{array}$ & Chinese & Filipino & Japanese & Korean & Vietnamese \\
\hline \hline Count & 473927 & 11388 & 1425 & 2898 & 3865 & 1549 & 949 & 702 \\
\hline Native born & NA & 1624 & 39 & 354 & 259 & 923 & 33 & 16 \\
\hline Foreign born & NA & 9764 & 1386 & 2544 & 1386 & 626 & 916 & 686 \\
\hline Age >1 - 19 & 6 & 0 & 0 & 0 & 0 & 0 & 0 & 0 \\
\hline Age 20-29 & 588 & 27 & 2 & 11 & 8 & 0 & 2 & 4 \\
\hline Age 30-39 & 8404 & 406 & 97 & 85 & 125 & 14 & 46 & 39 \\
\hline Age 40-49 & 34890 & 1591 & 219 & 442 & 536 & 105 & 154 & 135 \\
\hline Age 50-59 & 79702 & 2937 & 327 & 798 & 1054 & 258 & 289 & 211 \\
\hline Age 60-69 & 104501 & 2733 & 377 & 611 & 1079 & 282. & 227 & 157 \\
\hline Age 70-79 & 104973 & 1960 & 246 & 445 & 674 & 358 & 140 & 97 \\
\hline Age 80-99+ & 140856 & 1730 & 157 & 503 & 389 & 5310 & 910 & 59 \\
\hline
\end{tabular}

Figure 1

Demographics of Asian American and non-Hispanic white female breast cancer decedents, National Vital Statistics System 2003-2017

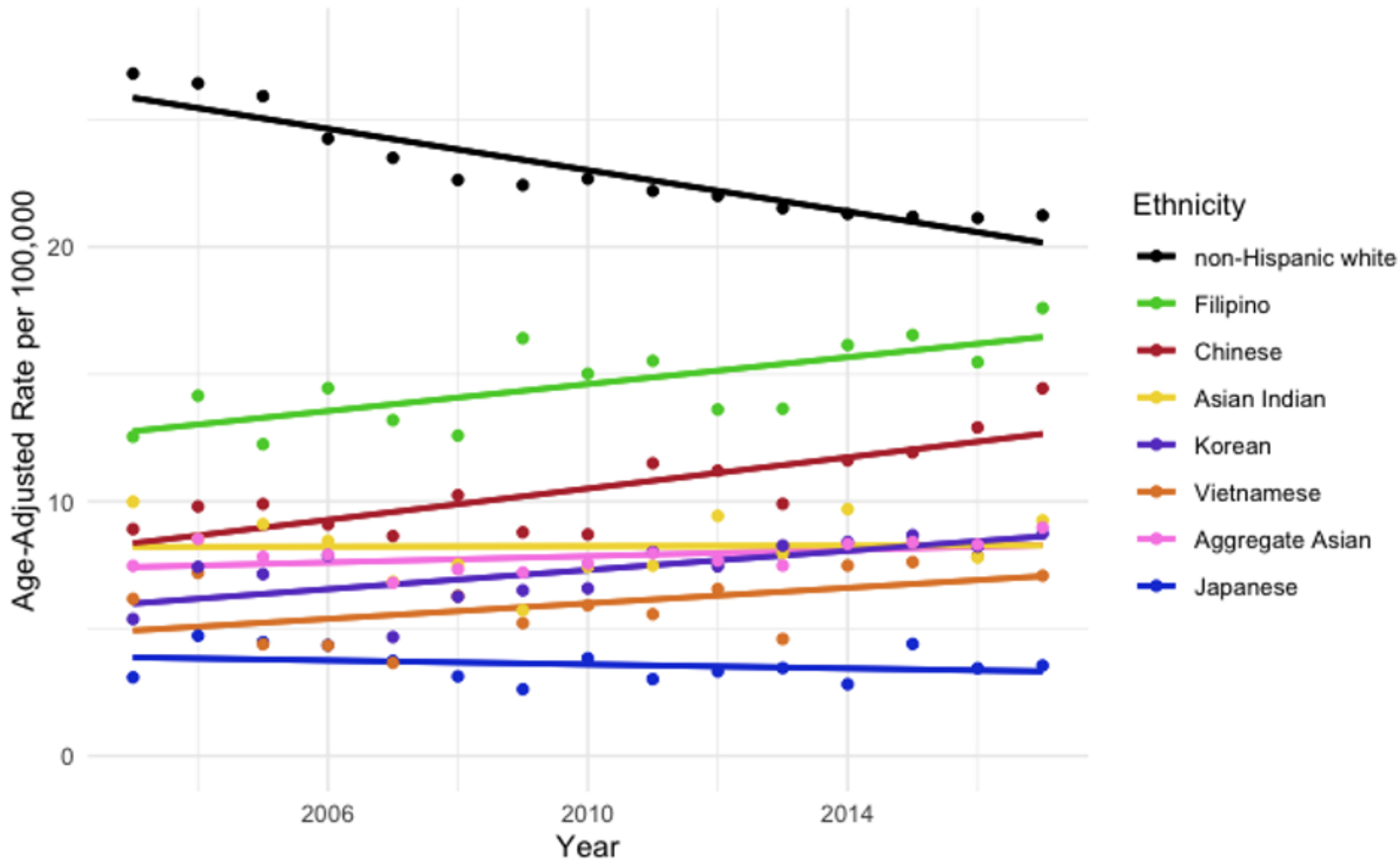

Figure 2 
Age-adjusted breast cancer mortality rates per 100,000 reported by Asian American group and nonHispanic whites female breast cancer decedents, National Vital Statistics System 2003-2017

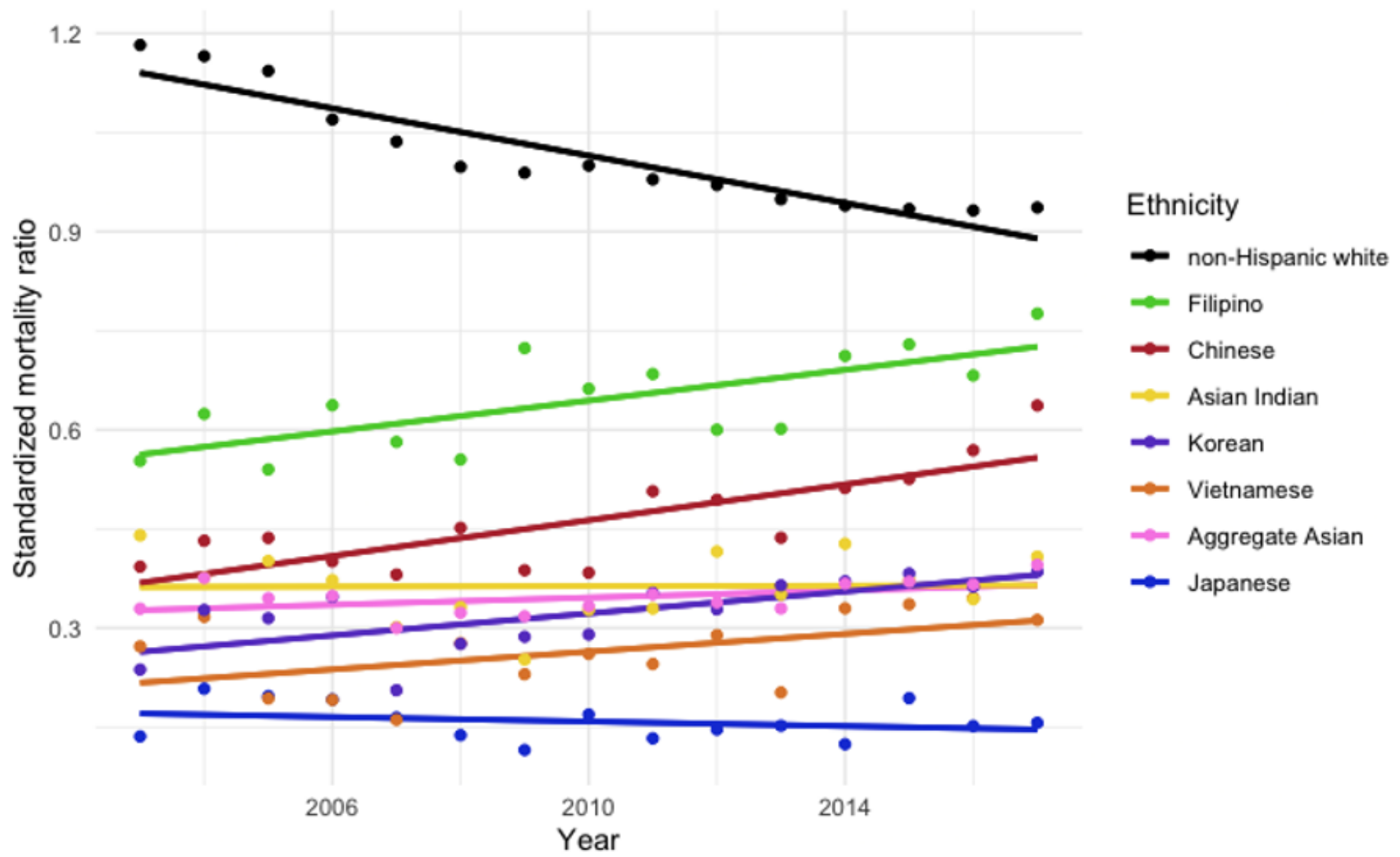

\section{Figure 3}

Age-adjusted mortality ratio standardized by the age-adjusted mortality rate for Asian American and nonHispanic Whites female breast cancer decedents, National Vital Statistics System 2003-2017, reference group American Community Survey 2010 


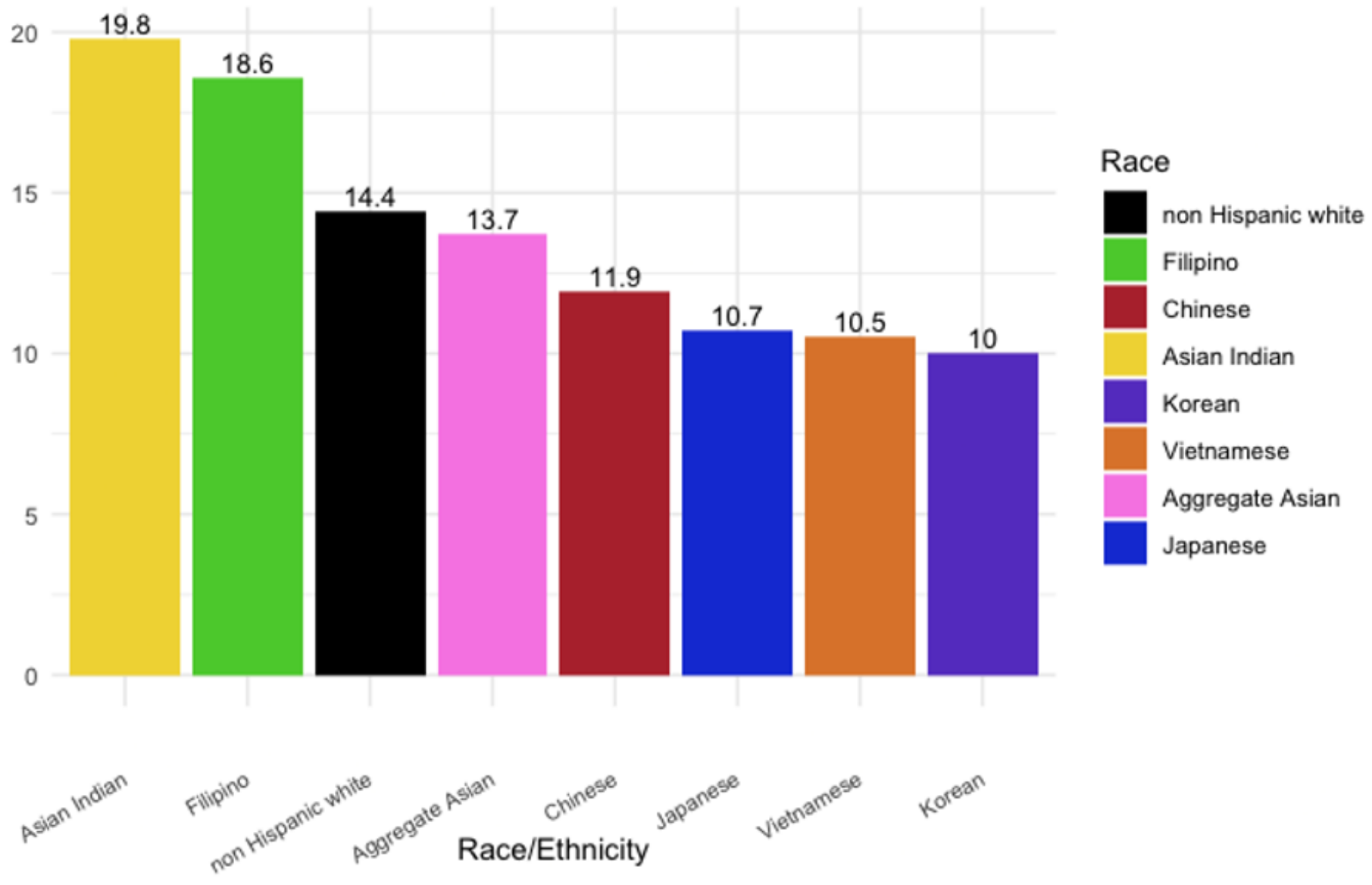

Figure 4

Proportionate mortality of breast cancer compared to all cancer mortality in Asian American and nonHispanic white women, National Vital Statistics System 2003-2017 


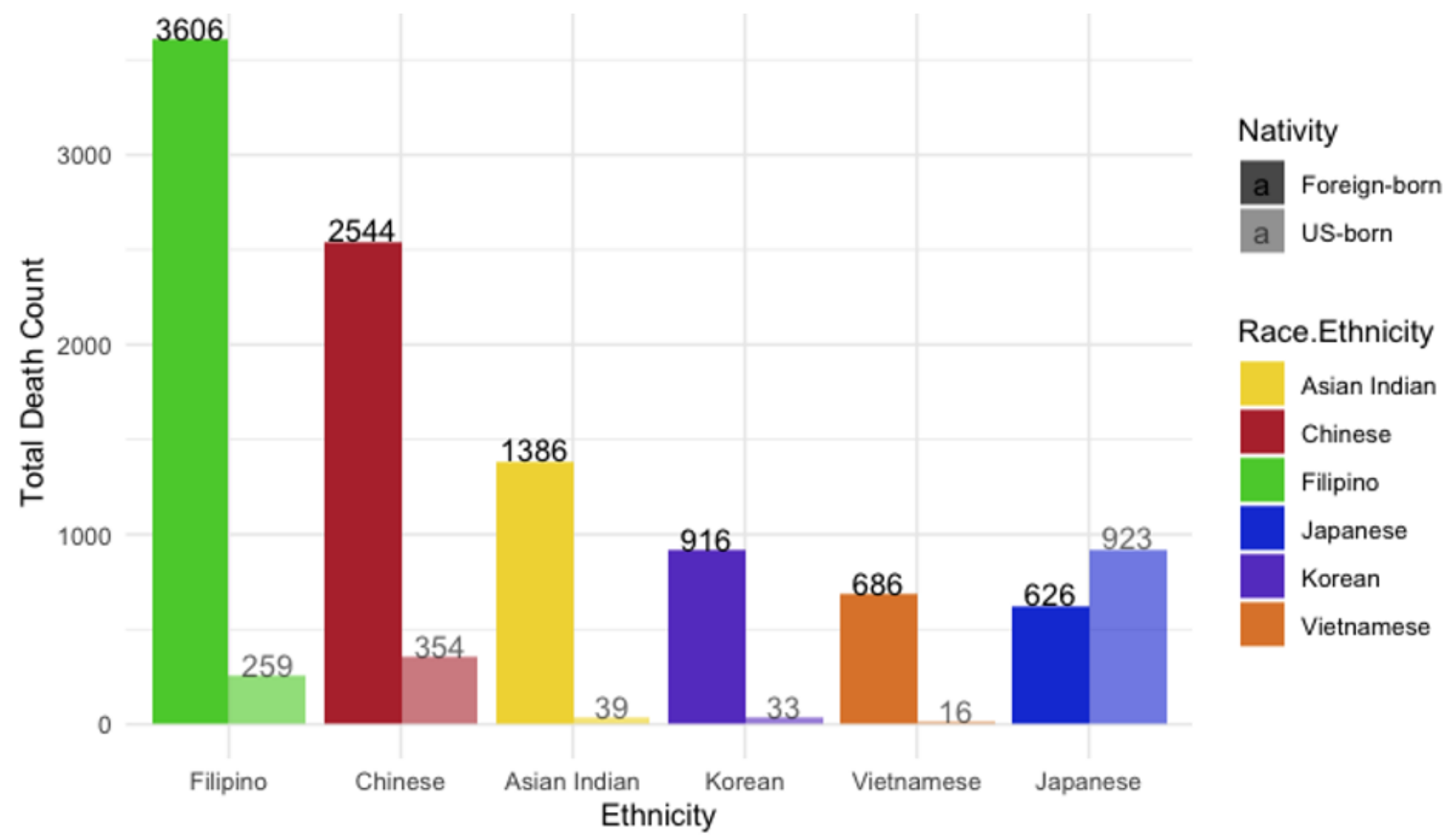

Figure 5

Total breast cancer deaths amongst Asian American groups, by nativity (US vs Foreign-born), National Vital Statistics System 2003-2017 


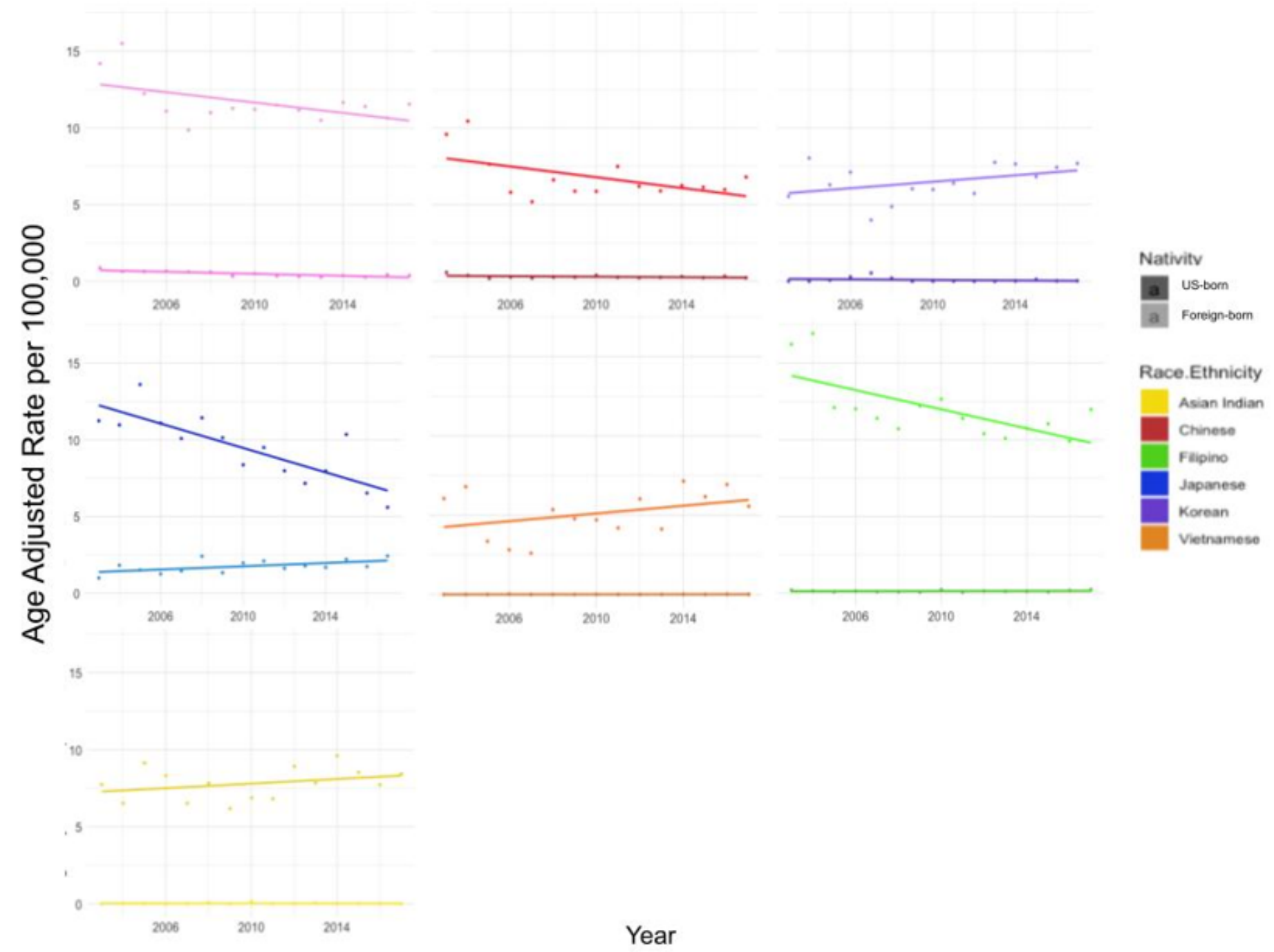

Figure 6

Breast cancer age-adjusted mortality rates per 100,000 for Asian American female decedents, by nativity (US-born vs foreign-born), National Vital Statistics System 2003-2017

\section{Supplementary Files}

This is a list of supplementary files associated with this preprint. Click to download.

- SupplementaryFigure1.docx

- SupplementaryFigure2.docx

- SupplementaryFigure3.docx 